\title{
Air pollutants degrade floral scents and increase insect foraging times
}

\author{
Jose D Fuentes ${ }^{\mathrm{a}, *}$, Marcelo Chamecki ${ }^{\mathrm{b}}$, T'ai Roulston ${ }^{\mathrm{c}}$, Bicheng Chen $^{\mathrm{a}}$, Kenneth R Pratt ${ }^{\mathrm{a}}$ \\ ${ }^{a}$ Department of Meteorology, The Pennsylvania State University, University Park, PA, USA \\ ${ }^{b}$ Department of Atmospheric and Oceanic Sciences, University of California at Los Angeles, Los Angeles, \\ $C A, U S A$ \\ ${ }^{c}$ Blandy Experimental Farm, University of Virginia, Boyce, VA, USA
}

\begin{abstract}
Flowers emit mixtures of scents that mediate plant-insect interactions such as attracting insect pollinators. Because of their volatile nature, however, floral scents readily react with ozone, nitrate radical, and hydroxyl radical. The result of such reactions is the degradation and the chemical modification of scent plumes downwind of floral sources. Large Eddy Simulations (LES) are developed to investigate dispersion and chemical degradation and modification of floral scents due to reactions with ozone, hydroxyl radical, and nitrate radical within the atmospheric surface layer. Impacts on foraging insects are investigated by utilizing a random walk model to simulate insect search behavior. Results indicate that even moderate air pollutant levels (e.g., ozone mixing ratios greater than 60 parts per billion on a per volume basis, ppbv) substantially degrade floral volatiles and alter the chemical composition of released floral scents. As a result, insect success rates of locating plumes of floral scents were reduced and foraging times increased in polluted air masses due to considerable degradation and changes in the composition of floral scents. Results also indicate that plant-pollinator interactions could be sensitive to changes in floral scent composition, especially if insects are unable to adapt to the modified scentscape. The increase in foraging time could have severe cascading and pernicious impacts on the fitness of foraging insects by reducing the time devoted to other necessary tasks.
\end{abstract}

\footnotetext{
${ }^{*}$ Corresponding author

Email address: jdfuentes@psu.edu (Jose D Fuentes)
} 
Keywords: Ozone; hydroxyl radical; pollination; pollution; hydrocarbons; fragrances; floral scents

2

\section{Introduction}

Plants emit a plethora of volatile organic compounds through organs such as roots, leaves, flowers, and fruits (Fuentes et al., 2000). Flowers typically release complex blends of volatile compounds (Knudsen et al., 2006) that give each plant species unique and characteristic fragrances. Although terpenoids, benzenoids, and fatty acid derivatives dominate the floral volatiles, the particular compounds produced by a given species vary among plant groups. For instance, flowers of the mustard plant family (Brassicaceae) typically emit nitrogencontaining compounds (Dobson, 2006) while flowers of the dogbane family (Apocynaceae) produce sulfur-containing compounds (Von Helversen et al., 2000). Once biosynthesized, emission rates of floral volatiles depend on biotic and abiotic factors. Biotic influences include flower ontogeny, pollination status, and insect infestation whereas abiotic conditions involve temperature, photosynthetically active radiation, and atmospheric carbon dioxide $\left(\mathrm{CO}_{2}\right)$ concentration. Therefore, in downwind areas from sources, ambient concentrations of floral volatiles should exhibit pronounced temporal and spatial variability. Once released into the atmosphere, floral hydrocarbons play key ecological roles such as attraction of pollinators and seed dispersers, defense against herbivores, protection against pathogens, and plant-to-plant signaling (Dötterl and Vereecken, 2010; Wright and Schiestl, 2009). Floral scents provide insect and animal pollinators the necessary cues about location and identity of plant species. Other ecological functions of volatile organic compounds include protection of foliage against abiotic stresses such as high solar radiation loadings and elevated temperature (Sharkey et al., 2001) or oxidative stress (Loreto et al., 2001).

One of the least studied aspects of floral volatile composition is the post-emission modifications caused by the reactions with atmospheric oxidants. As floral volatiles are transported by the wind from their sources, they can undergo rapid reactions with air pollutants such as ozone $\left(\mathrm{O}_{3}\right)$, hydroxyl radical $(\mathrm{OH})$, and nitrate radical $\left(\mathrm{NO}_{3}\right)$. As they traverse landscapes, reactions reduce the strength and the integrity of the chemical cues that floral scents provide 
to insects. Their reactions lead to the formation of secondary long-chain hydrocarbon products, some of which have common chemical characteristics to the parent floral fragrances (McFrederick et al., 2008). The destruction of primary signals and formation of secondary cues are poorly quantified, but are potentially crucial to understanding ecological and evolutionary conditions for organisms that depend on olfactory cues in polluted environments. Perturbations of scent signals hasten the destruction and also change the identity of scent plumes, both of which can affect the probability of detection by insects. Chemical degradation and changes in the composition of floral scents may increase the time that insects need to locate flowers, thereby potentially disrupting processes such as pollination. Flowers could alter the synthesis and the basal emissions of volatiles when exposed to heavy doses of ozone (e.g., > 150 ppbv, Loreto and Schnitzler (2010)) but such influences are not well known.

While previous studies examined the influences of habitat fragmentation (Bhattacharya et al., 2003; Montero-Castaño and Vilà, 2012), reductions in native habitat (Goulson et al., 2008), pesticide exposure (Whitehorn et al., 2012; Stanley et al., 2015), and diseases (Cameron et al., 2011) on insect communities, only limited attention (Pinto et al., 2007; McFrederick et al., 2008; Blande et al., 2010; Fuentes et al., 2013; Li and Blande, 2015) has been given to investigate the indirect impacts of air pollutants on the plant-insect interactions mediated via floral scents. Changes in composition and reduced amounts of the scent bouquet can lead to insects spending greater amounts of time foraging for food. With the continued changes in $\mathrm{OH}$ concentrations (Prinn et al., 2005) and in some cases increases in ground-level $\mathrm{O}_{3}$ concentrations in the rural atmosphere (Jaffe and Ray, 2007; Cooper et al., 2012; Parrish et al., 2013), the modified atmospheric chemistry of floral scents can interfere with their ecological roles. A pressing concern is that the alteration of the natural scentscape (McFrederick et al., 2009) by air pollutants may be adding to the stresses already contributing to the decline of pollinator populations (Biesmeijer et al., 2006) likely in response to increased pollinator foraging times and decreased pollination efficiency, and exposure to pesticide residues (Stanley et al., 2015). Despite the potential environmental and economic consequences of the disruption of insect pollination, no information exists to quantitatively evaluate direct and 
indirect influences of airborne pollutants on the ability of pollinators to sense plant chemical signals.

Therefore, this study evaluates the hypothesis that current levels of airborne pollutants sufficiently alter the composition and reduce the quantity of floral scents in such a manner that they perniciously increase insect foraging times. Several objectives are achieved to evaluate the hypothesis. Large Eddy Simulations (LES) coupled with chemical reactions allow us to determine degradation rates of individual floral volatiles as air parcels carry scents away from sources, exposed to different levels of air pollutants. Also, changes in the composition of floral volatile mixtures are calculated in response to different levels of air pollutants and distances travelled away from scent sources. Finally, foraging times of insects that have different thresholds of floral volatile detection are estimated in response to chemical degradation and modified composition of scent mixtures. A random walk model is developed to estimate insect foraging times as a function of modified scent plumes.

\section{Methods}

The understanding of how air pollutants deteriorate interactions between plants and insects requires knowledge of atmospheric chemistry and animal ecology and physiology. On the atmospheric side, knowledge of air turbulence is required to determine the transport of scents as they traverse the local landscape. Kinetics of floral volatiles released into the atmosphere are necessary to determine how individual compounds are altered by amounts and types of pollutants in the air mass. On the insect side, knowledge is required of the particular floral volatiles or mixtures of compounds that can be distinguished, concentration thresholds required to elicit a response, and the relative importance of scent over other sensory modalities (e.g., vision) in mitigating the interactions. Currently, no natural system is sufficiently well known to bring together all of the necessary information for reliable predictions in a realistic ecological framework. There is, however, existing theoretical and laboratory work indicating that current air pollutant levels may already be impacting important ecological interactions in natural environments (Fuentes et al., 2013; Farré-Armengol et al., 2016). We, 
therefore, seek to quantify the impacts of air-pollutant modified scents on plant-insect interactions by overlaying a spatially explicit numerical model of volatile degradation under specified environmental conditions (realistic wind velocities and air pollution regimes) with a foraging model that challenges insects to locate pollutant-modified scent plumes on the landscape.

Large eddy simulations, combined with air chemistry, allow us to determine the turbulent transport and chemical reactions of floral volatiles. The model predicts the time evolution of scent plumes under the influences of varying levels of turbulence mixing and chemical reactions at small spatial scales, thereby providing detailed information of floral scent plume composition with high temporal and spatial resolution (Figure 1). Therefore, in the absence of detailed information from field observations, LES outputs are the most reliable source of information for studying transport and chemical degradation of scent plumes. A random walk model is developed and applied to compute foraging times based on insect detection threshold of floral scents and modified scentscape.

\subsection{Description of the LES}

The LES model used in this study to determine dispersion of floral volatiles by the wind is described in detail elsewhere (Chamecki et al., 2009) and only a brief description is included here. In the LES, the filtered three-dimensional wind field $(\widetilde{\mathbf{u}})$ is determined from the solution of the filtered momentum and mass conservation equations which in vectorial form are expressed as ( $\nabla$ is the vector differential operator)

$$
\begin{aligned}
\nabla \cdot \widetilde{\mathbf{u}} & =0 \\
\frac{\partial \widetilde{\mathbf{u}}}{\partial t}+(\widetilde{\mathbf{u}} \cdot \nabla) \widetilde{\mathbf{u}} & =-\frac{1}{\rho} \nabla \widetilde{p}-\nabla \cdot \boldsymbol{\tau}_{\mathrm{sgs}} .
\end{aligned}
$$

In equation (2), the term $-(1 / \rho) \nabla \widetilde{p}$ is the filtered pressure gradient force and $\boldsymbol{\tau}_{\mathrm{sgs}}$ is the subgrid-scale (SGS) stress tensor representing the effect of the scales smaller than the LES grid size on the resolved wind field. Viscous effects are neglected on the basis of the large Reynolds number of the flows considered in this study. Additional filtered advection- 
diffusion-reaction equations were included in the LES model to represent the temporal variations of floral volatile concentrations $\left.\left(\partial \widetilde{\chi_{i}}\right] / \partial t\right)$

$$
\frac{\partial\left[\widetilde{\chi_{i}}\right]}{\partial t}+\nabla \cdot\left(\widetilde{\mathbf{u}}\left[\widetilde{\left.\chi_{i}\right]}\right)=-\nabla \cdot \boldsymbol{\pi}_{\chi_{i}}+Q_{\mathrm{src}, i}-k_{\mathrm{O}_{3}} \widetilde{\left[\chi_{i}\right]}\left[\mathrm{O}_{3}\right]-k_{\mathrm{HO}} \widetilde{\left[\chi_{i}\right]}[\mathrm{HO}]-k_{\mathrm{NO}_{3}} \widetilde{\left[\chi_{i}\right]}\left[\mathrm{NO}_{3}\right] .\right.
$$

In equation (3), $\widetilde{\left[\chi_{i}\right]}$ is the concentration of the $i^{\text {th }}$ floral volatile, $\boldsymbol{\pi}_{\chi_{i}}$ is the SGS floral volatile flux representing the mixing caused by turbulence scales not explicitly included in the simulation, $Q_{\mathrm{src}, i}$ represents the emission of scent from flower patches, and the three last terms on the right-hand side of equation (3) represent the loss of $\left.\widetilde{\left[\chi_{i}\right.}\right]$ due to reaction with $\mathrm{O}_{3}, \mathrm{OH}$, and $\mathrm{NO}_{3}$ with reaction rate coefficients $k_{\mathrm{O}_{3}}, k_{\mathrm{HO}}$, and $k_{\mathrm{NO}_{3}}$. To close the set of equations, the SGS momentum flux is parameterized using the Lagrangian scale-dependent dynamic Smagorinsky model (Bou-Zeid et al., 2005). The SGS floral volatile fluxes are then parameterized using the resulting SGS eddy viscosity and the SGS Schmidt number $\left(\mathrm{Sc}_{\tau}\right)$ which in this study is assumed to be 0.8 .

The momentum equations are discretized using a fully de-aliased, pseudo-spectral approach in the horizontal directions and a second-order centered finite-difference scheme in the vertical direction. Model lateral boundary conditions are periodic. A no-stress boundary condition is imposed at the top boundary and an equilibrium wall-model (Bou-Zeid et al., 2005 ) is used to parameterize the bottom boundary conditions. The advection-diffusionreaction equation (3) is discretized following a finite-volume method, with the bounded third-order upwind advection scheme SMART (Gaskell and Lau, 1988). The coupling between the pseudo-spectral discretization for momentum and the finite volume discretization for reactive scalars uses a conservative interpolation scheme (Chamecki et al., 2008). The lateral boundary conditions for the floral volatiles are specified as zero values for inflow and zero gradients for outflow boundary conditions and zero-flux conditions are specified at the top and bottom boundaries. The time integrations of wind velocity and floral volatile concentrations are carried out using the second-order Adams-Bashforth scheme (Peyret and Taylor, 1983). The flow is driven by an imposed mean pressure gradient, which is adjusted to generate different wind conditions (corresponding to friction velocity $u_{*}=0.1 \mathrm{~m} \mathrm{~s} s^{-1}$ and 
$\left.u_{*}=0.2 \mathrm{~m} \mathrm{~s}^{-1}\right)$. Neutral thermal stratification is assumed in all simulations. The resulting vertical variations of averaged zonal wind speed $(\bar{u})$ and standard deviation of the vertical velocity $\left(\sigma_{w}\right)$ are included in Figure 2 for the assumed $u_{*}$ values.

The simulation domain consists of a volume of $1000 \mathrm{~m} \times 350 \mathrm{~m} \times 50 \mathrm{~m}\left(L_{x} \times L_{y} \times L_{z}\right)$, covered by a sparse vegetation of height $h=1 \mathrm{~m}$ (represented by a constant surface roughness $\left.z_{0}=0.05 \mathrm{~m}\right)$. This domain is discretized using $400 \times 140 \times 100$ grid points, resulting in a grid resolution of $2.5 \mathrm{~m} \times 2.5 \mathrm{~m} \times 0.5 \mathrm{~m}$. Flower patches are randomly distributed within an area of $180 \mathrm{~m} \times 250 \mathrm{~m}$ near the upwind edge of the domain (Figure 1 ). Five hundred flower patches (with $2.5 \mathrm{~m} \times 2.5 \mathrm{~m}$ each) are included in the simulations. Flowers are asummed to emit blends of volatiles comprised of $\beta$-caryophyllene, $\beta$-ocimene, $\beta$-myrcene, linalool, and $\alpha$-pinene (i.e., $i=1, \ldots, 5$ in Equation 3 and Table 1). The chosen volatiles (Table 1) are common components of floral fragrances and play numerous ecological functions, including attracting pollinators (Byers et al., 2014), herbivores (Mayer et al., 2008), and parasitoids of herbivores (Ozawa et al., 2008). Herbivore feeding on plants enhances production of $\beta$ myrcene as a way of attracting parasitoids to control the herbivores (Van Poecke et al., 2001). Basal emission rates $\left(E_{s, i}\right)$ for a nominal temperature $T_{s}=303 \mathrm{~K}$ (Table 1 ) for each floral volatile are determined from experimental data (Wright et al., 2005), assuming a leaf area index equal to 2. Effective emission rates $\left(E_{i}\right)$ corresponding to a flower temperature of $T=298 \mathrm{~K}$ are used in the simulation, and are determined employing equation (4)

$$
E_{i}(T)=E_{s, i} \exp \left[\beta\left(T-T_{s}\right)\right]
$$

where $\beta$ is a constant taken as $0.06 \mathrm{~K}^{-1}$. The floral volatile emission per unit volume required in equation (3) is then calculated as $Q_{\mathrm{src}, i}=E_{i}(T) / d z$, where $d z$ is the vertical grid spacing used in the simulation. Each simulation is executed for 2 hours with a time step $d t=0.1 \mathrm{~s}$. Data analyses are performed for the final hour of the simulations, when gas concentration fields are statistically stationary.

\subsection{Model of insect foraging flight}

Random walk models are frequently used to represent the foraging behavior of animals (Codling et al., 2008). Typically, resources are represented as points distributed throughout 
Table 1: Floral volatiles, emission rates, and reaction rate coefficients used in the model simulations. $\ddagger$ : Values of reaction rate coefficients were obtained from Atkinson et al. (1999).

\begin{tabular}{lccccc}
\hline Index & Species & $\begin{array}{c}\text { Emission rate }\left(E_{s}\right) \\
\left(\mathrm{nmoles} \mathrm{m}^{-2} \mathrm{~min}^{-1}\right)\end{array}$ & $\begin{array}{c}K_{\mathrm{O}_{3}} \\
\left(\mathrm{~cm}^{3} \mathrm{molec}^{-1} \mathrm{~s}^{-1}\right)^{\ddagger}\end{array}$ & $\begin{array}{c}K_{\mathrm{OH}} \\
\left(\mathrm{cm}^{3} \mathrm{molec}^{-1} \mathrm{~s}^{-1}\right)^{\ddagger}\end{array}$ & $\begin{array}{c}K_{\mathrm{NO}_{3}} \\
\left(\mathrm{~cm}^{3} \mathrm{molec}^{-1} \mathrm{~s}^{-1}\right)^{\ddagger}\end{array}$ \\
\hline \hline 1 & $\beta$-Caryophyllene & 15 & $1.10 \times 10^{-14}$ & $2.00 \times 10^{-10}$ & $1.90 \times 10^{-11}$ \\
2 & $\beta$-Ocimene & 82 & $5.40 \times 10^{-16}$ & $2.52 \times 10^{-10}$ & $2.20 \times 10^{-11}$ \\
3 & $\beta$-Myrcene & 25 & $4.70 \times 10^{-16}$ & $2.13 \times 10^{-10}$ & $1.27 \times 10^{-11}$ \\
4 & Linalool & 6.5 & $4.30 \times 10^{-16}$ & $1.59 \times 10^{-10}$ & $1.12 \times 10^{-11}$ \\
5 & $\alpha$-Pinene & 10 & $8.09 \times 10^{-17}$ & $5.33 \times 10^{-11}$ & $6.16 \times 10^{-12}$ \\
\hline
\end{tabular}

the landscape and random walks are then used to represent the movement of animals as they survey the surroundings in search of resources. A radius of detection is typically assigned to the forager and once a resource is within this radius then the search is considered successful. In this typical approach, the existence of chemical cues such as scent plumes is either neglected or is included in the detection radius of the insect. Therefore, external factors (such as turbulence and air pollutant levels) that influence composition and spatial extent of the floral scent plumes cannot be studied. In the present work, we address this issue by explicitly representing the spatial extent of floral scent plumes that are generated from the LES model outputs.

From all the possible random walk models, Lévy walks have received significant attention (Viswanathan et al., 1999; Reynolds and Rhodes, 2009; Reynolds, 2010). Under some specific circumstances, Lévy walks represent optimal search strategies (Viswanathan et al., 1999; Raposo et al., 2009). More recently, the idea of composite searches (Plank and James, 2008) in which insects invest foraging times in resource rich areas has gained attention. Basically, insects move back and forth between two strategies: an intensive search is adopted in regions rich in resources and an extensive foraging strategy is adopted elsewhere. Thus, insects first use extensive searches to locate resources, and then they alternate to intensive searches within areas with resources. If searches are not successful then insects move back to extensive 
foraging to cover larger areas in search of other resource rich areas. Even in composite search strategies, Lévy walks seem to be the most profitable approach (Reynolds and Bartumeus, 2009). Despite recent criticism regarding the optimality of Lévy walks as a foraging strategy (Pyke, 2015), the approach is still useful as an idealized model to investigate the effects of environmental characteristics on insect foraging.

We adopt the Lévy walk to represent insects searching for floral scent plumes. In the context of composite searches, this can be viewed as the extensive strategy of locating the first resource location within an unknown landscape (Reynolds and Bartumeus, 2009; Nolting et al., 2015). In the model, insect flights are determined by a step length $(l)$ and a horizontal angle $(\theta)$. Step lengths are drawn from a power-law distribution given by

$$
P(l)=\left(\frac{l}{l_{0}}\right)^{-\mu} .
$$

In equation (5), $l_{0}$ is the minimum step length and $\mu$ is a parameter whose value ranges from 1 to 3 . Note that $\mu=3$ corresponds to Brownian motion and $\mu=2$ is a super-diffusive Lévy walk. The model with $\mu=2$ represents optimal search strategies (Viswanathan et al., 1999) and it is used in the current study. Horizontal angles are drawn from a uniform distribution.

Two source distributions representing landscapes with different amounts of resources are investigated. In the first case, only one simulated plume is included, representing a landscape with scarce resources. Insects are released from the downwind corner of the simulation domain $(x=1000 \mathrm{~m}$ and $y=-175 \mathrm{~m})$, corresponding to a distance of nearly $1 \mathrm{~km}$ from the center of the flower patch (Figure 1, top panel). A landscape rich in resources is also considered. For that purpose, eight copies of the scent plumes produced by the LES are placed in a circular pattern around the insect release location (Figure 1, bottom panel). In both cases, the initial height $(z)$ of the insects is set to $1 \mathrm{~m}$, and this value is kept constant during the insect flights. Each insect flight step is broken into substeps of size $l_{0}\left(l_{0}=1 \mathrm{~m}\right.$ is used here) and, after each substep, the local floral scent concentration is compared to the insect detection threshold for a given compound to decide whether the insect is capable of recognizing the scent plume at that location. If the gas concentration is greater than the detection threshold, the flight ends and the insect is considered successful in locating the 
scent plume. In the model, it is assumed that insects fly at a constant speed of $2 \mathrm{~m} \mathrm{~s}^{-1}$ and terminate their flights if the scent plume is not found within 3 hours. For each scenario (see description in Section 2.3), 18 instantaneous LES-generated scent plumes are considered. For each plume, a total of 5,000 insect flights are considered, and statistics are computed over the accumulated 90,000 flights. Simulations are performed for detection thresholds varying from $0.1 \mathrm{pptv}$ to $25 \mathrm{pptv}$. These detection thresholds are within the lowest-observed responses of insects (Dusenbery, 1992).

\subsection{Pollution scenarios}

Six scenarios (Table 2) are considered to determine changes in scents in response to varying levels of air pollutants as air parcels travel away from flowers. The first scenario (Sc0) considers no air pollutants to determine the spatial variation of floral volatiles away from sources in response to turbulent transport and to serve as the basis for comparison with the rest of scenarios. The second scenario (Sc1) includes 20 ppbv of $\mathrm{O}_{3}, 0.02$ part per trillion on a volume basis (pptv) $\left(5.0 \times 10^{5}\right.$ radicals $\left.\mathrm{cm}^{-3}\right)$ of $\mathrm{OH}$, and 0 pptv of $\mathrm{NO}_{3}$. This scenario may be viewed as the prevailing $\mathrm{O}_{3}$ levels during pre-industrial times (Marenco et al., 1994), with limited photochemical activity (and hence low OH levels) and no nitrogen oxides to generate $\mathrm{NO}_{3}$. The third scenario $(\mathrm{Sc} 2)$ involves the levels of $0.2 \mathrm{pptv}\left(5.0 \times 10^{6}\right.$ radicals $\mathrm{cm}^{-3}$ ), $40 \mathrm{ppbv}$, and $0 \mathrm{pptv}$ of $\mathrm{OH}, \mathrm{O}_{3}$, and $\mathrm{NO}_{3}$, respectively. The fourth scenario (Sc3) uses the levels of $0.3 \mathrm{pptv}\left(1.0 \times 10^{7}\right.$ radicals $\left.\mathrm{cm}^{-3}\right), 60 \mathrm{ppbv}$, and $1 \mathrm{pptv}$ for $\mathrm{HO}, \mathrm{O}_{3}$, and $\mathrm{NO}_{3}$, respectively. The fifth scenario (Sc4) involves the levels of $0.40 \mathrm{pptv}\left(2.0 \times 10^{7}\right.$ radicals $\mathrm{cm}^{-3}$ ), $80 \mathrm{ppbv}$, and $2 \mathrm{pptv}$ for $\mathrm{OH}, \mathrm{O}_{3}$, and $\mathrm{NO}_{3}$, respectively. The last scenario (Sc5) involes the levels of $0.80 \mathrm{pptv}\left(2.0 \times 10^{7}\right.$ radicals $\left.\mathrm{cm}^{-3}\right), 120 \mathrm{ppbv}$, and $5 \mathrm{pptv}$ for $\mathrm{OH}, \mathrm{O}_{3}$, and $\mathrm{NO}_{3}$, respectively. We choose these last two scenarios to reflect the broad ranges in air pollutant deviations from pre-industrial times (Marenco et al., 1994; Prinn et al., 2005) to current summertime conditions in regions such as the eastern United States where maximum $\mathrm{O}_{3}$ levels can sometimes exceed $120 \mathrm{ppbv}$ (Fiore et al., 2002). Pollutants are assumed to logarithmically vary with altitude, and the values listed here are specified at a height $z=1.5 \mathrm{~m}$ (the value at the top of the domain is twice the value at $1.5 \mathrm{~m}$ ). For 
simplicity and convenience, for a given scenario, the ambient mixing ratios of $\mathrm{OH}, \mathrm{O}_{3}$, and $\mathrm{NO}_{3}$ remain constant in time and space throughout the course of model simulations.

Table 2: Ambient mixing ratios of the ozone, hydroxyl radical, and nitrate radical included in the scenarios of the numerical simulations.

\begin{tabular}{cccc}
\hline Scenario & $\begin{array}{c}\mathrm{O}_{3} \\
(\text { ppbv })\end{array}$ & $\begin{array}{c}\mathrm{HO} \\
(\text { pptv })\end{array}$ & $\begin{array}{c}\mathrm{NO}_{3} \\
(\text { pptv })\end{array}$ \\
\hline \hline $\mathrm{Sc0}$ & 0 & 0.00 & 0 \\
$\mathrm{Sc} 1$ & 20 & 0.02 & 0 \\
$\mathrm{Sc} 2$ & 40 & 0.20 & 0 \\
$\mathrm{Sc} 3$ & 60 & 0.30 & 1 \\
$\mathrm{Sc} 4$ & 80 & 0.40 & 2 \\
$\mathrm{Sc5}$ & 120 & 0.80 & 5 \\
\hline
\end{tabular}

\subsection{Data analysis techniques}

In total, twelve LES runs are done to include the six air pollutant scenarios under the influences of two turbulence levels. Average floral volatile concentrations are calculated to determine the chemical degradation of scent plumes in response to varying levels of air pollutants. For each floral scent $(i=1, \ldots, 5$, Table 1$)$ and scenario $\left(S c_{j}, j=0, \ldots, 5\right)$, temporal averages are performed (for periods defined from initial time $\left(T_{0}\right)$ to some later time $\left(T_{f}\right)$ ) and crosswind direction to yield mean gas concentration as a function of $x$ and $z$

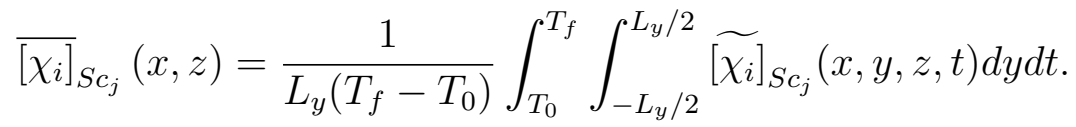

Resulting average scent concentrations are reported in two ways. First, to illustrate the effects of air pollutants on scent concentrations downwind from sources, gas concentrations are normalized to concentrations for the scenario without air pollutants $\left({\overline{\left[\chi_{i}\right.}}_{N_{j}}(x, z)\right)$ and are determined using Equation (7) for scent species $i=1, \ldots, 5$.

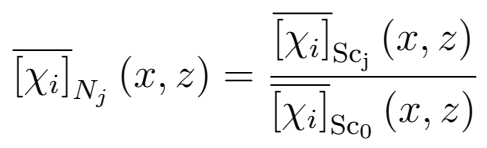


Second, to emphasize the effects of air pollutants on the changes in the composition of scent plumes, fractional composition $\left({\overline{\left[\chi_{i}\right]}}_{F_{j}}(x, z)\right)$ of scent plumes are computed using Equation (8) for each scenario.

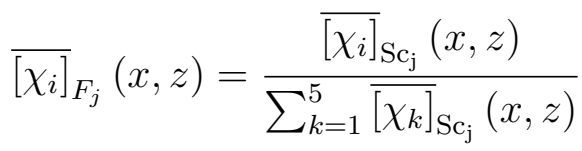

Only values for the height of insect flight $(z=1.0 \mathrm{~m})$ are reported below (i.e., ${\overline{\left[\chi_{i}\right.}}_{N_{j}}(x, 1.0 \mathrm{~m})$, \left.${\overline{\left[\chi_{i}\right]}}_{F_{j}}(x, 1.0 \mathrm{~m})\right)$. For the fractional composition, values are reported at the discrete downwind distances $(x)$ of $200,300,400$, and $800 \mathrm{~m}$.

For insect foraging times, statistics are calculated for each flower volatile and for each air pollution scenario individually. Calculations are done separately for landscapes scarce and rich in scent resources. Summary statistics are presented for the discovery of floral plumes based on three detection thresholds. The cumulative distributions of insect discovery times of floral plumes and the proportion of insects discovering floral plumes within 3 hours are presented.

\section{Results}

\subsection{Chemical degradation of floral volatiles}

The chemical degradation of floral scents depends on the reactivity of volatiles and ambient levels of air pollutants. For the chosen air pollutant levels, floral chemical species exhibit a broad range of lifetimes (for the reaction with $\mathrm{O}_{3}$, the individual floral scent $\left(\chi_{i}\right)$ lifetime is defined as $\tau_{\chi_{i}, \mathrm{O}_{3}}=\left(K_{\chi_{i}, \mathrm{O}_{3}}\left[\mathrm{O}_{3}\right]\right)^{-1}$; similar expressions can be defined for $\tau_{\chi_{i}, \mathrm{OH}}$ and $\tau_{\chi_{i}, \mathrm{NO}_{3}}$ ). Concerning the $\mathrm{O}_{3}$ reactivity, $\beta$-caryophyllene is the most reactive scent and its lifetime decreases from 12 to 2 minutes for $\mathrm{O}_{3}$ levels between 5 and 120 ppbv (Figure 3). Linalool, $\beta$-ocimene, and $\beta$-myrcene have an intermediate reactivity with respect to $\mathrm{O}_{3}$ and their lifetimes vary from 200 to 10 minutes when $\mathrm{O}_{3}$ changes from 5 to 120 ppbv. In these simulations, $\alpha$-pinene is the least reactive with $\mathrm{O}_{3}$ and its lifetime changes from 30 to 1 hours for $\mathrm{O}_{3}$ levels between 5 and 120 ppbv (Figure 3). With regard to the $\mathrm{OH}$ reactivity, $\beta$ ocimene, $\beta$-myrcene, and $\beta$-caryophyllene are the most short lived scents and their lifetimes range from 50 hours to 5 minutes when $\mathrm{OH}$ changes from 0.001 to 0.8 pptv. Concerning 
the $\mathrm{NO}_{3}$ reactivity, $\beta$-ocimene and $\beta$-caryophyllene are the most reactive species and their lifetimes range from 18 hours to 5 minutes as $\mathrm{NO}_{3}$ varies from 0.01 to 5 pptv. In polluted air masses (i.e., $[\mathrm{OH}]>0.3 \mathrm{pptv}$ ), all floral scents have lifetimes of few $(<30)$ minutes (Figure $3)$.

Source strength of floral volatiles, levels of air turbulence, and rates of chemical reactions dictate the three-dimensional characteristics of the scents downwind from sources. For example, Figure 4 displays iso-surfaces of time averaged scent mixing ratios in the threedimensional space (i.e., a surface formed by all the points with a chosen constant gas mixing ratio value) downwind from the chosen floral patches. Blue iso-surfaces represent mixing ratios of $0.6 \mathrm{pptv}$ for myrcene and $\beta$-caryophyllene (under the influences of scenarios Sc0, Sc3, and Sc5), indicating that all the points inside the blue surface have scent levels above $0.6 \mathrm{pptv}$ and all the points outside the surface have scent mixing ratios below 0.6 pptv. The volume inside the blue iso-surface represents the portion of the plume that an insect with a threshold detection of 0.6 pptv can detect. Similarly, the volume inside the purple iso-surfaces represents the portion of the scent plume that insects with a detection threshold of 4.8 pptv can detect.

Ambient scent distribution downwind from sources is inversely related to turbulence levels (Figure 4). For the same floral volatile emission rates, scent levels are higher under the influence of low air turbulence (this feature is clearly noticeable on the purple plumes). This effect is due to the reduced dilution rates of scents caused by lower mean wind speeds associated with the low turbulence (Figure 2). Also, under the influences of the two adopted levels of turbulence and no chemistry, relatively elevated gas mixing ratios prevailed across the landscape, with scent levels above $3.2 \mathrm{pptv}$ extending as far as $300 \mathrm{~m}$ away from flowers (note that the source ends at $x=200 \mathrm{~m}$, so the location at $x=500 \mathrm{~m}$ is $300 \mathrm{~m}$ downwind from the flower patch). Sufficient levels (>0.4 pptv) of $\beta$-myrcene (Figure $4 \mathrm{~A}$ ) and $\beta$ caryophyllene (Figure 4B) reached about $800 \mathrm{~m}$ downwind from floral volatile sources. Such scent spatial distribution patterns and abundances were deemed adequate for most insects to locate the floral scent plumes (Dusenbery, 1992). In effect, the resulting spatial distribution 
of floral scents provided information on the effective plume "footprint" of a particular floral patch. For polluted conditions (scenarios Sc3 and Sc5), the plumes of floral volatiles such as $\beta$-myrcene, with medium reactivity, could only reach $400 \mathrm{~m}$ downwind from sources (Figure 4). For the highly reactive compounds such as $\beta$-caryophyllene, sufficient levels were only found near flowers. Therefore, in polluted air masses, the "volume" of scent plumes is drastically reduced due to the chemical reactions, thereby making it harder for insects to locate food.

Air pollutant levels and reactivity of floral scents exert control on the spatial extent of floral volatile transported away from sources. Horizontal cross sections (Figure 5) provide the spatial distribution of floral scents downwind from sources under the influences of different levels of air pollutants. To some extent, they represent the scentscape that insects can detect while foraging for food resources. The unpolluted case ( $\mathrm{Sc} 0)$ serves as a basis for comparison and shows similar spatial distributions of $\beta$-myrcene and $\beta$-caryophyllene (see color scales, Figure 5), confirming that the difference in source strength between the two compounds (about $60 \%$, see Table 1) is not the dominant factor in determining their spatial distributions. Under moderate levels of air pollutant (Sc3), significant levels of $\beta$-myrcene ( $1 \mathrm{pptv})$ can reach about $800 \mathrm{~m}$ downwind from floral sources whereas similar levels of $\beta$-caryophyllene reach at most $100 \mathrm{~m}$ downwind from sources. The most dramatic effect occurs in polluted air masses (Sc6) when plumes of $\beta$-myrcene remain within $400 \mathrm{~m}$ of scent sources; in contrast, plumes of $\beta$-caryophyllene can only be found directly above the floral patches.

While foraging for resources most insects use non-directional sensory cues and instantaneous plumes of scents to identify areas that warrant searches (Nolting et al., 2015; Bell, 1990). Instantaneous scent plumes provide information to allow foraging insects to directly orient themselves to habitat resources and determine the appropriate search strategy (i.e., intensive or extensive search modes). Time-averaged plumes (Figure 5) differ substantially compared to instantaneous ones (Figure 6). Whereas time-averaged scent plumes provide relatively smooth scent concentration gradients along horizontal transects, instantaneous flo- 
ral fragrance plumes reveal greater heterogeneity in the spatial distribution of gases. Some areas can be almost devoid of floral scents while the contiguous surroundings exhibit high loading of scents (e.g., scenarios Sc3 and Sc5 for $\beta$-caryophyllene, Figure 6). The characteristic features in the spatially heterogeneous gas distribution in instantaneous plumes result in response to erratic turbulent fluctuations that allow for the rapid transport of gases. In the instantaneous plumes, the intensity of the spatiotemporal scent fluctuations increases with air turbulence (data not shown). Consequently, at any given location and time, scent concentrations within plumes can erratically and substantially vary compared to the timeaveraged plumes (compare Figure 5 with Figure 6). These results (Figure 6) suggest that foraging insects likely use olfactory information provided by instantaneous plumes to influence search behavior at the habitat level that can impact search strategies at the patch, and search at the patch can affect foraging for individual resources (Bell, 1990).

Ambient scent levels downwind from sources depend on rates of chemical destruction and turbulence intensity. Under the influences of the assumed air turbulence conditions $\left(\mathrm{u}_{*}\right.$ $=0.1 \mathrm{~m} \mathrm{~s}^{-1}$ and $\mathrm{u}_{*}=0.2 \mathrm{~m} \mathrm{~s}^{-1}$ ), the normalized time-averaged concentrations of floral volatiles (i.e., ${\overline{\left[\chi_{i}\right.}}_{N_{j}}$ for floral scents $i=1, \ldots, 5$ and air pollution scenarios $j=1, \ldots, 5$, see Methods Section) provide a qualitative measure of the influences of chemical reactions on the distances traveled by scent plumes away from sources. Compounds such as $\beta$-myrcene and $\beta$-caryophyllene can exhibit different abundances along transects from downwind of sources in response to the reactivities of floral volatiles (Figure 7). For example, under the influences of low air pollutant concentrations (Sc1), only 75 to $80 \%$ of the emitted $\beta$ myrcene reaches $800 \mathrm{~m}$ away from floral sources, when $u_{*}=0.1 \mathrm{~m} \mathrm{~s}^{-1}$ and $u_{*}=0.2 \mathrm{~m} \mathrm{~s}^{-1}$, respectively. In contrast, only $5 \%$ of the emitted $\beta$-caryophyllene reaches $800 \mathrm{~m}$ when $\mathrm{u}_{*}=$ $0.1 \mathrm{~m} \mathrm{~s}^{-1}$ and $400 \mathrm{~m}$ away from sources when $\mathrm{u}_{*}=0.2 \mathrm{~m} \mathrm{~s}^{-1}$. For highly polluted conditions (Sc6), only approximately $25 \%$ of the original $\beta$-myrcene remains within distances of $100 \mathrm{~m}$ downwind from floral sources (Figure 7). As air pollutant concentrations increase, amounts of scents exponentially decrease with distance away from floral sources. Based on these results (Figure 7), it is concluded that reductions in the amounts of floral scents transported 
away from sources can impair the ability of insects locating floral scents due to the reductions of olfactory cues below the insect detection thresholds.

\subsection{Modification of floral volatile mixtures}

Generalist insects such as honeybees respond to floral bouquets instead of a specific scent (Wright et al., 2005; Raguso, 2008). Also, generalist insects respond to compound blends but detect ratios as indicators to judge potential success of locating resources (Raguso, 2008). Because of the different reaction rates for each floral volatiles, however, the composition of the floral scents can change as they react with air pollutants, thereby altering the floral bouquet. To show the potential changes in the ratios of these components, LES results were used to track the composition of scent plumes as they traveled away from from sources. Figure 8 depicts the differences between the floral composition at the source and the composition of scent plumes at several downwind distances from sources. While the initial composition of the scent was comprised of $60 \% \beta$-ocimene, $20 \% \beta$-myrcene, $8 \% \beta$-caryophyllene, $7 \%$ $\beta$-pinene, and $5 \%$ linalool at the source, it is evident (Figure 8) the fragrance composition changed substantially as air parcels traveled downwind in polluted conditions. For instance, at $800 \mathrm{~m}$ away from sources, $\beta$-pinene, rather than $\beta$-ocimene, became the predominant compound in the floral mixture, due to the slower reaction rates. Even by the short traveled distance of $250 \mathrm{~m}$, the floral bouquet did not include $\beta$-caryophyllene due to its destruction via chemical reactions. Therefore, the results indicate that the insects associated with original floral volatile blends would become increasingly 'confused' and unable to distinguish the appropriate composition of the volatile mixture away from the source under polluted conditions. The addition of pollutants, however, makes this task of identifying floral mixtures more laborious as the scent composition changes much more rapidly with increasing levels of oxidants.

For those insects that have evolved to rely upon the unique signature of a specific flower, a change in the composition of these scents could be troubling, depending upon how sensitive their antennae are to detecting particular compounds Skiri et al. (2005) and their tolerance for shifts in relative concentration among plume components. Many insect species hone 
in on specific scents because it increases their likelihood of being consistently rewarded. If particular flowers are proven to be reliable sources of nectar for foraging insects then they can train themselves to that specific scent, what is known as flower constancy (Gegear and Laverty, 2005). In polluted conditions, however, the plume of floral volatiles may no longer be recognized as such because its composition no longer corresponds to the scent that insects associate with a particular flower. Moreover, because plant odors mediate both mutualistic and antagonistic relationships between plants and insects, a disruption in the communication system could either help or hurt plants depending on which insects are most affected. In cases where antagonists and mutualists respond to different volatiles from the same plant (e.g., Andrews et al. (2007)), the outcome will depend partly on the reactivity of the different compounds. More generally, however, mutualistic relationships may be more sensitive to disruption because they typically rely on repeated tracking of scent to source (e.g., pollinators and natural enemies searching for new resources) whereas antagonists such as herbivores may find sufficient resources at a single resource once discovered and rely less on long-distance plant signals from that point forward.

\subsection{Potential impact on insect success and foraging times}

Air pollutants, type of hydrocarbons, detection thresholds of insects, and number of floral patches on the landscape impact insect discovery times of floral sources. These effects are illustrated in Figure 9, where the cumulative number of insects that locate the scent plume is displayed as a function of foraging time (up to the limit of 3 hours). Each panel corresponds to a combination of hydrocarbon used by insects and corresponding insect detection threshold limit, and results under different pollution scenarios are compared for landscapes scarce and rich in resources (solid and dashed lines, respectively). By itself, detection threshold sets severe constraints on how far away scent plumes can be detected when transported downwind from sources. When there is only a single floral patch on the landscape (Figure 9 - solid lines), the proportion of foragers that locate the scent within 180 minutes in the unpolluted environment decreases from about $80 \%$ with a detection threshold of 0.1 pptv (Figure 9A-C) to approximately $20 \%$ in an unpolluted environment with a detection threshold of 3.9 pptv 
(Figures 9G-I). These results are due to the fact that insects with low olfactory detection threshold can detect greater foraging areas in response to greater scent loadings (Figure 6). Therefore, olfactory detection threshold values explain the broad computed foraging times for the investigated scents (Figure 9).

The reactivity of the hydrocarbon being modeled strongly influences the effect of air pollutants on scent plume detectability. For the most reactive floral volatile, $\beta$-caryophyllene, even modest levels of air pollutants (e.g., $\left[\mathrm{O}_{3}\right]=20 \mathrm{ppbv},[\mathrm{OH}]=0.02 \mathrm{pptv}$ ) can have dramatic effects on both discovery times and probability of discovery within 180 minutes, thereby reducing the likelihood of discovery by $65 \%$ and increasing the discovery time from about 10 minutes to approximately 180 minutes for the first $20 \%$ of foragers to locate the scent plume (Figures 9C and F). As air pollutant levels increase, the size of the scent plume diminishes (Figure 6) which increases the insect foraging times. For a hydrocarbon of intermediate reactivity such as $\beta$-myrcene, the plume discovery can broadly differ across all pollutant levels (Figures 9B and E), while for $\alpha$-pinene, the least reactive hydrocarbon included in the foraging model, a notable effect of air pollutants is only observed at an intermediate level of detectability (i.e., 0.6 pptv, Figure 9D). Again, size of scent plumes and characteristic features of spatial gas distribution (Figure 6) impact the insect discovery times of flower patches. Number of floral patches present throughout the landscape also influences the outcome of foraging trials. As floral patches become prevailingly common (Figure 9 dashed lines), most foragers encounter scent plumes within 180 minutes. At the extreme, over $50 \%$ of foragers encounter scent plumes within 15 minutes while searching for the most reactive compound in unpolluted environments, but similar numbers of foragers take about 60 minutes for discovery of scent plumes under modest pollution levels (Figure 9F). Therefore, these results indicate that floral scent reactivity, pollutant levels, and detection thresholds all strongly mediate the ability of insects to locate scent plumes.

In our foraging model, insects searched for a particular scent in the landscape, following it when it was encountered above a threshold concentration. Because insects are capable of associative learning (Hollis and Guillette, 2015), they could potentially learn to follow 
the altered plume to the original plume and reach the reward. Second order conditioning (associating one stimulus with another stimulus) has been demonstrated in the laboratory with honeybees exposed consecutively to two distinct odors (Hussaini et al., 2007). It would be challenging, however, for an insect to learn distinct stimuli under polluted conditions as the odor would be continuously changing with distance and with diurnal patterns of pollutant concentrations. While we cannot currently evaluate the likelihood of an insect learning to track the altered plume, we recognize this effect is an interesting study area with broad implications for insect response to environmental change.

\section{Summary and Conclusions}

This study concludes that even moderate air pollutant levels (e.g., $\left[\mathrm{O}_{3}\right]>60$ ppbv) substantially degrade the chemical constituents of released floral scents. The chemical degradation of floral volatiles contributes to substantial reductions in the concentrations of scents as they are transported away from sources. Decreases in scent abundances away from sources show steeper decreases with increasing levels of air pollutants. In the most polluted air masses $\left(\left[\mathrm{O}_{3}\right]=120 \mathrm{ppbv}\right)$, compounds such as $\beta$-ocimene decrease to $25 \%$ of the original abundance within a downwind distance of $100 \mathrm{~m}$ from sources whereas $\beta$-caryophyllene retains only $10 \%$ of the original amount within $50 \mathrm{~m}$ of sources. In all scenarios examined, concentrations of the studied floral volatiles substantially decrease in response to increasing levels of air pollutants and rates of scent destruction depend on gas reactivity with respect to $\mathrm{O}_{3}, \mathrm{OH}$, and $\mathrm{NO}_{3}$. Because individual components of floral scents degrade at different rates, the scent itself changes as a function of reactant concentrations and time evolution of the scent plumes. At downwind distances of $800 \mathrm{~m}$, the least reactive compounds (e.g., $\alpha$-pinene) dominate the composition of scents whereas the more reactive compounds (e.g., $\beta$-caryophyllene) are chemically destroyed.

The likelihood of foraging insects discovering a particular flower patch depends on air pollutant levels, antennal sensitivity, and the component(s) of the floral scent that the insects recognize and follow. Taken together, these variables determine the perceptual footprint of scent plumes, and the size of that footprint determines both the speed and the likelihood of 
patch discovery. Our simulations indicate that air pollution will have the greatest impact on patch discovery time when highly reactive volatiles elicit foraging responses at low scent concentrations.

Increased discovery time of flower patches may have pernicious effects on insects. Many insect species rely on flowers for food, mating and oviposition sites, and follow odor trails to locate them (Byers et al., 2014; Chen et al., 2009; Cunningham et al., 2004; Maia et al., 2014; Urru et al., 2011). The longer insects must forage for resources, the less efficient they become and the greater risk they face from predators and parasites (e.g., Goodell (2003)). Thus, pollution may reduce insect fitness through changes in food detectability. Such effects however, are likely to be species specific and context specific in severity. Insects following relatively rare scent plumes in their foraging environment may be more detrimentally affected than insects relying on locally common odor plumes. Similarly, insects needing to locate a scent plume only once to complete a life stage, such as ovipositing in a flower just prior to death (Dunn et al., 2014), might be less affected than those that must repeatedly locate flowers, given that the inherent advantage of insects finding a bigger plume target would be compounded by repetition. Additionally, insects that wander throughout the landscape searching for odor plumes each time a resource is needed may be more affected than centralplace foragers that locate resource patches and return to them repeatedly using spatial memory (Menzel et al., 2005). The severity of the effects may also be mitigated by whether an insect navigates using single compounds or complex plumes as stimuli. Insects tracking single scents will be able to follow a scent trail as long as it occurs above the detection threshold. For insects following a floral plume, however, detectability depends on both the reactivity of the individual components of that plume and the ability of insects to recognize and track the plume despite variation in plume composition.

Modifications of floral scent quality and quantity can have broad impacts on plantinsect interactions, not just insect fitness. The most reactive compounds in our study, $\beta$-caryophyllene and $\beta$-myrcene, are common components of floral volatiles and play diverse ecological roles, such as attracting pollinators, herbivores, and parasitoids of herbivores. If 
mutualist insects such as pollinators are less efficient at finding hosts then visitation to host plants may be less frequent and pollination services may be reduced. Similarly, if predators and parasites are less able to follow the scent trail released by plants that are attacked by herbivores then the ecological services they provide to plants will also be diminished.

Overall, we predict that existing air pollution levels in urban and industrial corridors can have deleterious impacts on insect foraging efficiency and on plant-insect interactions. Levels of ambient pollutants, types of volatiles comprising the scent plume, sensitivity of insect antennae to plume constituents, the abundance of host plants in the environment and the air conditions (windy versus calm) of the location may all differentially impact the extent of the negative ecological impacts.

\section{Acknowledgments}

The Pennsylvania State University Institutes of Energy and the Environment (PSIEE) provided funding to complete this research. JDF Fuentes also acknowledges support from the National Science Foundation (grant numbers GEO 0914597 and AGS 1417914). Authors thank the Editor and two anonymous reviewers for the comments that improved the manuscript. Data used to create the figures in this work are available from the authors' upon request (e-mail: jdfuentes@psu.edu). 


\section{References}

Andrews, E. S., Theis, N., Adler, L. S., 2007. Pollinator and herbivore attraction to cucurbita floral volatiles. Journal of chemical ecology 33 (9), 1682-1691.

Atkinson, R., Baulch, D., Cox, R., Hampson Jr, R., Kerr, J., Rossi, M., Troe, J., 1999. Evaluated kinetic and photochemical data for atmospheric chemistry, organic species: Supplement vii. Journal of Physical and chemical reference Data 28 (2), 191-393.

Bell, W. J., 1990. Searching behavior patterns in insects. Annual review of entomology 35 (1), $447-467$.

Bhattacharya, M., Primack, R. B., Gerwein, J., 2003. Are roads and railroads barriers to bumblebee movement in a temperate suburban conservation area? Biological Conservation 109 (1), 37-45.

Biesmeijer, J. C., Roberts, S., Reemer, M., Ohlemüller, R., Edwards, M., Peeters, T., Schaffers, A., Potts, S., Kleukers, R., Thomas, C., et al., 2006. Parallel declines in pollinators and insect-pollinated plants in britain and the netherlands. Science 313 (5785), 351-354.

Blande, J. D., Holopainen, J. K., Li, T., 2010. Air pollution impedes plant-to-plant communication by volatiles. Ecology Letters 13 (9), 1172-1181.

Bou-Zeid, E., Meneveau, C., Parlange, M. B., 2005. A scale-dependent Lagrangian dynamic model for large eddy simulation of complex turbulent flows. Phys. Fluids 17, 025105, doi:10.1063/1.1839152.

Byers, K. J., Bradshaw, H., Riffell, J. A., 2014. Three floral volatiles contribute to differential pollinator attraction in monkeyflowers (mimulus). The Journal of experimental biology $217(4), 614-623$.

Cameron, S. A., Lozier, J. D., Strange, J. P., Koch, J. B., Cordes, N., Solter, L. F., Griswold, T. L., 2011. Patterns of widespread decline in north american bumble bees. Proceedings of the National Academy of Sciences 108 (2), 662-667. 
Chamecki, M., Meneveau, C., Parlange, M. B., 2008. A hybrid spectral/finite-volume algorithm for large-eddy simulation of scalars in the atmospheric boundary layer. BoundaryLayer Meteorol. 128, 473-484.

Chamecki, M., Meneveau, C., Parlange, M. B., 2009. Large eddy simulation of pollen transport in the atmospheric boundary layer. J. Aerosol Sci. 40, 241-255.

Chen, C., Song, Q., Proffit, M., Bessière, J.-M., Li, Z., Hossaert-McKey, M., 2009. Private channel: a single unusual compound assures specific pollinator attraction in ficus semicordata. Functional Ecology 23 (5), 941-950.

Codling, E. A., Plank, M. J., Benhamou, S., 2008. Random walk models in biology. Journal of the Royal Society Interface 5 (25), 813-834.

Cooper, O. R., Gao, R.-S., Tarasick, D., Leblanc, T., Sweeney, C., 2012. Long-term ozone trends at rural ozone monitoring sites across the united states, 1990-2010. Journal of Geophysical Research: Atmospheres (1984-2012) 117 (D22).

Cunningham, J. P., Moore, C. J., Zalucki, M. P., West, S. A., 2004. Learning, odour preference and flower foraging in moths. Journal of Experimental Biology 207 (1), 87-94.

Dobson, H. E., 2006. Relationship between floral fragrance composition and type of pollinator. Biology of floral scent, 147-198.

Dötterl, S., Vereecken, N., 2010. The chemical ecology and evolution of bee-flower interactions: a review and perspectives. the present review is one in the special series of reviews on animal-plant interactions. Canadian Journal of Zoology 88 (7), 668-697.

Dunn, D. W., Jandér, K. C., Lamas, A. G., Pereira, R. A., 2014. Mortal combat and competition for oviposition sites in female pollinating fig wasps. Behavioral Ecology, 1-7. doi:10.1093/beheco/aru191.

Dusenbery, D. B., 1992. Sensory ecology. 
Farré-Armengol, G., Peñuelas, J., Li, T., Yli-Pirilä, P., Filella, I., Llusia, J., Blande, J. D., 2016. Ozone degrades floral scent and reduces pollinator attraction to flowers. New Phytologist 209 (1), 152-160.

Fiore, A. M., Jacob, D. J., Bey, I., Yantosca, R. M., Field, B. D., Fusco, A. C., Wilkinson, J. G., 2002. Background ozone over the united states in summer: Origin, trend, and contribution to pollution episodes. Journal of Geophysical Research: Atmospheres (19842012) 107 (D15), ACH-11.

Fuentes, J. D., Gu, L., Lerdau, M., Atkinson, R., Baldocchi, D., Bottenheim, J., Ciccioli, P., Lamb, B., Geron, C., Guenther, A., et al., 2000. Biogenic hydrocarbons in the atmospheric boundary layer: a review. Bulletin of the American Meteorological Society 81 (7), 15371575.

Fuentes, J. D., Roulston, T. H., Zenker, J., 2013. Ozone impedes the ability of a herbivore to find its host. Environmental Research Letters 8 (1), 014048.

Gaskell, P. H., Lau, A. K. C., 1988. Curvature-compensated convective transport: SMART, a new boundedness-preserving transport algorithm. Int. J. Numer. Methods Fluids 8, 617641.

Gegear, R. J., Laverty, T. M., 2005. Flower constancy in bumblebees: a test of the trait variability hypothesis. Animal Behaviour 69 (4), 939-949.

Goodell, K., 2003. Food availability affects osmia pumila (hymenoptera: Megachilidae) foraging, reproduction, and brood parasitism. Oecologia 134 (4), 518-527.

Goulson, D., Lye, G. C., Darvill, B., 2008. Decline and conservation of bumble bees. Annu. Rev. Entomol. 53, 191-208.

Hollis, K., Guillette, L., 2015. What associative learning in insects tells us about the evolution of learning and fixed behavior. International Journal of Comparative Psychology. Volume 28. 
Hussaini, S. A., Komischke, B., Menzel, R., Lachnit, H., 2007. Forward and backward secondorder pavlovian conditioning in honeybees. Learning \& Memory 14 (10), 678-683.

Jaffe, D., Ray, J., 2007. Increase in surface ozone at rural sites in the western us. Atmospheric Environment 41 (26), 5452-5463.

Knudsen, J. T., Eriksson, R., Gershenzon, J., Ståhl, B., 2006. Diversity and distribution of floral scent. The Botanical Review 72 (1), 1-120.

Li, T., Blande, J. D., 2015. Associational susceptibility in broccoli: mediated by plant volatiles, impeded by ozone. Global change biology 21 (5), 1993-2004.

Loreto, F., Mannozzi, M., Maris, C., Nascetti, P., Ferranti, F., Pasqualini, S., 2001. Ozone quenching properties of isoprene and its antioxidant role in leaves. Plant Physiology $126(3), 993-1000$.

Loreto, F., Schnitzler, J.-P., 2010. Abiotic stresses and induced bvocs. Trends in plant science $15(3), 154-166$.

Maia, A. C. D., de Lima, C. T., Navarro, D. M. d. A. F., Chartier, M., Giulietti, A. M., Machado, I. C., 2014. The floral scents of nymphaea subg. hydrocallis (nymphaeaceae), the new world night-blooming water lilies, and their relation with putative pollinators. Phytochemistry 103, 67-75.

Marenco, A., Gouget, H., Nédélec, P., Karcher, F., et al., 1994. Evidence of a long-term increase in tropospheric ozone from pic du midi data series: Consequences: Positive radiative forcing. Journal of Geophysical Research: Atmospheres (1984-2012) 99 (D8), 16617-16632.

Mayer, C. J., Vilcinskas, A., Gross, J., 2008. Pathogen-induced release of plant allomone manipulates vector insect behavior. Journal of chemical ecology 34 (12), 1518-1522.

McFrederick, Q. S., Fuentes, J. D., Roulston, T., Kathilankal, J. C., Lerdau, M., 2009. Effects of air pollution on biogenic volatiles and ecological interactions. Oecologia 160 (3), $411-420$. 
McFrederick, Q. S., Kathilankal, J. C., Fuentes, J. D., 2008. Air pollution modifies floral scent trails. Atmospheric Environment 42 (10), 2336-2348.

Menzel, R., Greggers, U., Smith, A., Berger, S., Brandt, R., Brunke, S., Bundrock, G., Hülse, S., Plümpe, T., Schaupp, F., Schüttler, E., Stach, S., Stindt, J., Stollhoff, N., Watzl, S., 2005. Honey bees navigate according to a map-like spatial memory. Proceedings of the National Academy of Sciences of the United States of America 102 (8), 3040-3045.

Montero-Castaño, A., Vilà, M., 2012. Impact of landscape alteration and invasions on pollinators: a meta-analysis. Journal of ecology 100 (4), 884-893.

Nolting, B. C., Hinkelman, T. M., Brassil, C. E., Tenhumberg, B., 2015. Composite random search strategies based on non-directional sensory cues. Ecological Complexity 22, 126 138.

URL http://www.sciencedirect.com/science/article/pii/S1476945X15000355

Ozawa, R., Shiojiri, K., Sabelis, M. W., Takabayashi, J., 2008. Maize plants sprayed with either jasmonic acid or its precursor, methyl linolenate, attract armyworm parasitoids, but the composition of attractants differs. Entomologia Experimentalis et Applicata 129 (2), 189-199.

Parrish, D., Law, K. S., Staehelin, J., Derwent, R., Cooper, O., Tanimoto, H., Volz-Thomas, A., Gilge, S., Scheel, H.-E., Steinbacher, M., et al., 2013. Lower tropospheric ozone at northern midlatitudes: Changing seasonal cycle. Geophysical Research Letters 40 (8), $1631-1636$.

Peyret, R., Taylor, T. D., 1983. Computational methods for fluid flow. Springer Berlin Heidelberg.

Pinto, D. M., Blande, J. D., Nykänen, R., Dong, W.-X., Nerg, A.-M., Holopainen, J. K., 2007. Ozone degrades common herbivore-induced plant volatiles: does this affect herbivore prey location by predators and parasitoids? Journal of Chemical Ecology 33 (4), 683-694. 
Plank, M., James, A., 2008. Optimal foraging: Levy pattern or process? Journal of The Royal Society Interface 5 (26), 1077-1086.

Prinn, R., Huang, J., Weiss, R., Cunnold, D., Fraser, P., Simmonds, P., McCulloch, A., Harth, C., Reimann, S., Salameh, P., et al., 2005. Evidence for variability of atmospheric hydroxyl radicals over the past quarter century. Geophysical Research Letters 32 (7).

Pyke, G. H., 2015. Understanding movements of organisms: it's time to abandon the lévy foraging hypothesis. Methods in Ecology and Evolution 6 (1), 1-16.

Raguso, R. A., 2008. Wake up and smell the roses: the ecology and evolution of floral scent. Annual Review of Ecology, Evolution, and Systematics, 549-569.

Raposo, E., Buldyrev, S., Da Luz, M., Viswanathan, G., Stanley, H., 2009. Lévy flights and random searches. Journal of Physics A: mathematical and theoretical 42 (43), 434003.

Reynolds, A., Bartumeus, F., 2009. Optimising the success of random destructive searches: Lévy walks can outperform ballistic motions. Journal of theoretical biology 260 (1), 98103.

Reynolds, A. M., 2010. Bridging the gulf between correlated random walks and lévy walks: autocorrelation as a source of lévy walk movement patterns. Journal of the Royal Society Interface, rsif20100292.

Reynolds, A. M., Rhodes, C. J., 2009. The lévy flight paradigm: random search patterns and mechanisms. Ecology 90 (4), 877-887.

Sharkey, T. D., Chen, X., Yeh, S., 2001. Isoprene increases thermotolerance of fosmidomycinfed leaves. Plant Physiology 125 (4).

Skiri, H., Stranden, M., Sandoz, J.-C., Menzel, R., Mustaparta, H., 2005. Associative learning of plant odorants activating the same or different receptor neurones in the moth heliothis virescens. Journal of Experimental Biology 208 (4), 787-796. 
Stanley, D. A., Smith, K. E., Raine, N. E., 2015. Bumblebee learning and memory is impaired by chronic exposure to a neonicotinoid pesticide. Scientific reports 5 .

Urru, I., Stensmyr, M. C., Hansson, B. S., 2011. Pollination by brood-site deception. Phytochemistry 72 (13), 1655-1666.

Van Poecke, R. M., Posthumus, M. A., Dicke, M., 2001. Herbivore-induced volatile production by arabidopsis thaliana leads to attraction of the parasitoid cotesia rubecula: chemical, behavioral, and gene-expression analysis. Journal of Chemical Ecology 27 (10), 1911-1928.

Viswanathan, G., Buldyrev, S. V., Havlin, S., Da Luz, M., Raposo, E., Stanley, H. E., 1999. Optimizing the success of random searches. Nature 401 (6756), 911-914.

Von Helversen, O., Winkler, L., Bestmann, H., 2000. Sulphur-containing perfumes attract flower-visiting bats. Journal of Comparative Physiology A 186 (2), 143-153.

Whitehorn, P. R., OConnor, S., Wackers, F. L., Goulson, D., 2012. Neonicotinoid pesticide reduces bumble bee colony growth and queen production. Science 336 (6079), 351-352.

Wright, G. A., Lutmerding, A., Dudareva, N., Smith, B. H., 2005. Intensity and the ratios of compounds in the scent of snapdragon flowers affect scent discrimination by honeybees (apis mellifera). Journal of Comparative Physiology A 191 (2), 105-114.

Wright, G. A., Schiestl, F. P., 2009. The evolution of floral scent: the influence of olfactory learning by insect pollinators on the honest signalling of floral rewards. Functional Ecology $23(5), 841-851$. 


\section{Figure captions}

Figure 1. (Top) Configuration of the Large Eddy Simulation domain and distribution of flowers releasing scents to attract insects, and (bottom) spatial distribution of scent plumes and location foraging insects.

Figure 2. Vertical variations of wind speed (top) and standard deviation of the vertical wind speed (bottom) under the influences of friction velocity $\left(u_{*}\right)$ of 0.1 and $0.2 \mathrm{~m}$ per s.

Figure 3. Lifetimes of floral volatiles as a function of reactivity with respect to (top) ozone, (middle) hydroxyl radical, and (bottom) nitrate radical under the the influences of the oxidant levels shown on the insets (right hand side). Labels placed on top of symbols are 1: $\beta$-Caryophyllene, 2: $\beta$-Ocimene, 3: $\beta$-Myrcene, 4: Linalool, and 5: $\alpha$-Pinene.

Figure 4. Three-dimensional scent plume characteristics for (top) $\beta$-myrcene and (bottom) $\beta$-caryophyllene under the influences of pollution scenarios (i) Sc0, (ii) Sc3, and (iii) Sc5 and friction velocity values of $0.1 \mathrm{~m} \mathrm{~s}^{-1}$ and $0.2 \mathrm{~m} \mathrm{~s}^{-1}$. Iso-surfaces corresponding to gas mixing ratios of 0.6 pptv (blue) and 4.8 pptv (purple) are illustrated.

Figure 5. Horizontal cross sections of (left) $\beta$-myrcene and (right) $\beta$-caryophyllene timeaveraged plumes for pollution scenarios (i) Sc0, (ii) Sc3, and (iii) Sc5. The friction velocity of $0.1 \mathrm{~m}$ per s was used in the LES. The cross section is at $1.0 \mathrm{~m}$ above the surface.

Figure 6. Horizontal cross sections of (left) $\beta$-myrcene and (right) $\beta$-caryophyllene instantaneous plumes for pollution scenarios (i) Sc0, (ii) Sc3, and (iii) Sc5. The friction velocity of $0.1 \mathrm{~m}$ per s was used in the LES. The cross section is at $1.0 \mathrm{~m}$ above the surface.

Figure 7. Fraction of (a) $\beta$-myrcene and (b) $\beta$-caryophyllene remaining as a function of downwind distance traveled from the source after reacting with hydroxyl radicals, ozone, and nitrate radicals for the four scenarios considered in the modeling study using friction velocity values of $0.1 \mathrm{~m}$ per $\mathrm{s}$ and $0.2 \mathrm{~m}$ per $\mathrm{s}$. The values are averaged at $1.0 \mathrm{~m}$ above the surface.

Figure 8. Modification of plume composition as compounds travel and react from sources to downwind areas for (i) no pollution, (ii) $60 \mathrm{ppb}$ of ozone, and (iii) $120 \mathrm{ppb}$ of ozone using $u_{*}$ of $0.1 \mathrm{~m}$ per s. (B) Modification of scents as compounds travel and react from sources to 
downwind areas for (i) no pollution, (ii) $60 \mathrm{ppb}$ of ozone, and (iii) $120 \mathrm{ppb}$ of ozone using $u_{*}$ of $0.2 \mathrm{~m}$ per s. The values are averaged at $1.0 \mathrm{~m}$ above the surface.

Figure 9. Cumulative distribution function of the foraging times required for insects to locate scent plumes in a landscape with scarce resources (solid lines) and rich in resources (dashed lines). Pollution scenarios are represented by different colors: Sc0 (black), Sc1 (red), Sc2 (green), Sc3 (blue), Sc4 (gray), and Sc5 (orange). Each figure (e.g., Figure A) reports the cumulative distribution function of foraging times for insects with a given threshold detection of $\alpha$-pinene, $\beta$-myrcene, and $\beta$-caryophyllene. 

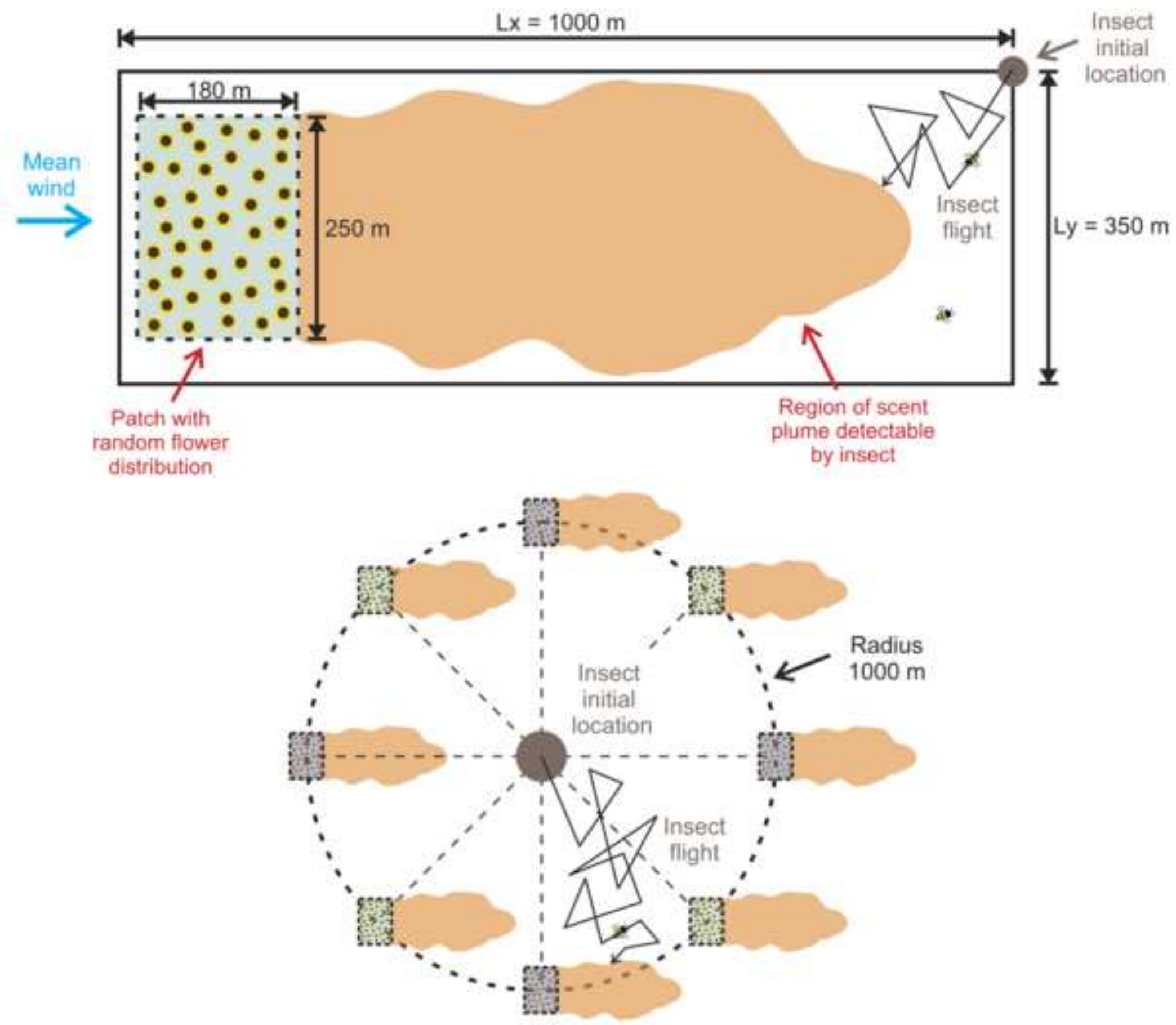
Figure2

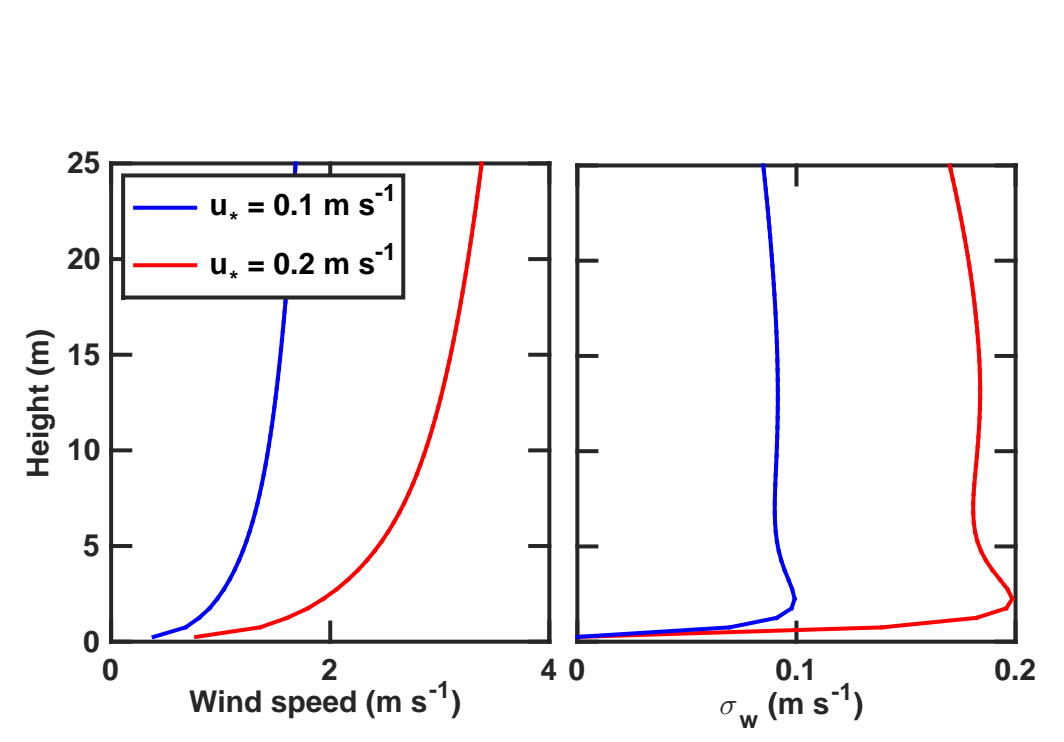

\section{Eure2}

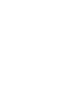

Fi

. 


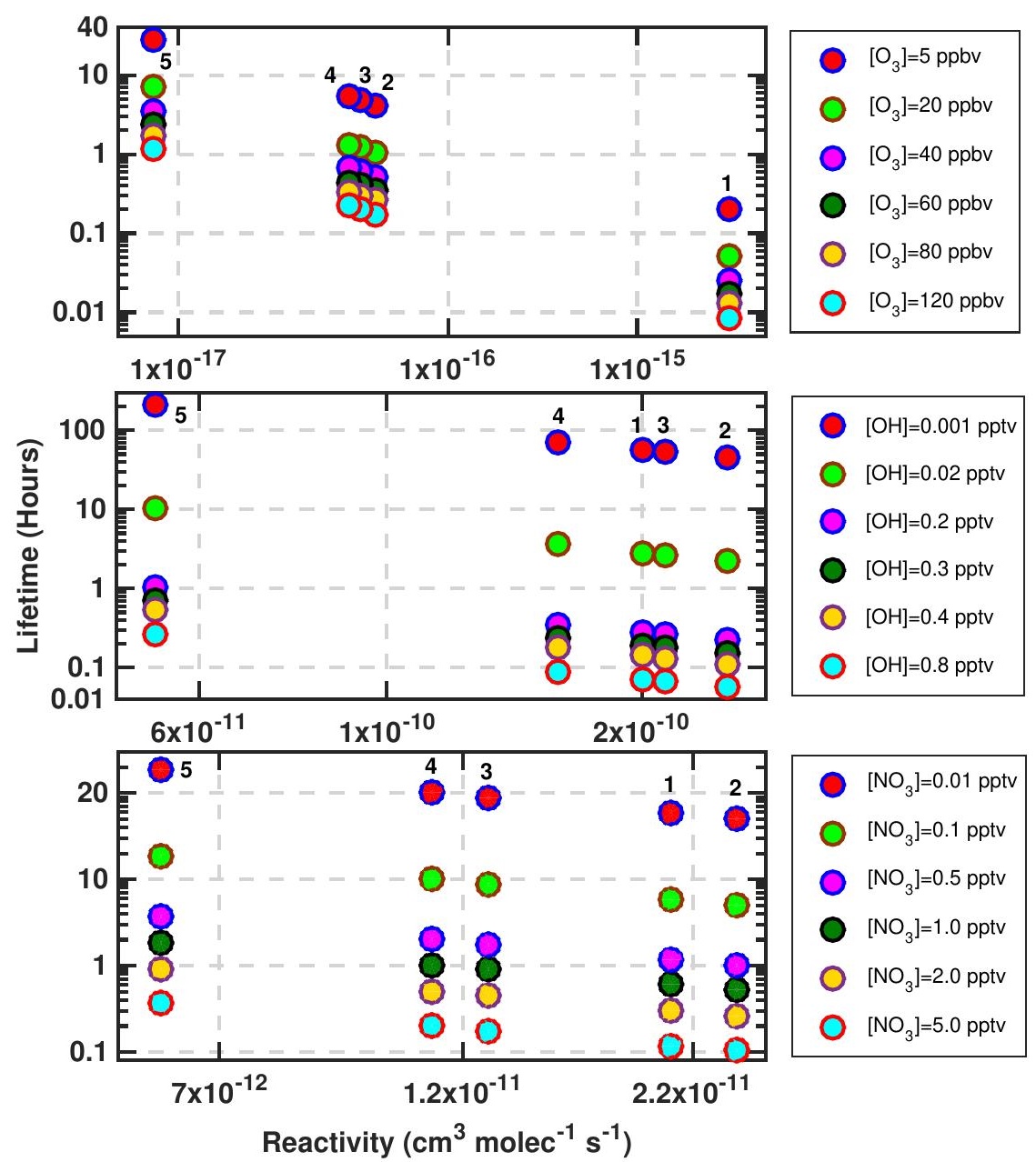

- $\left[\mathrm{O}_{3}\right]=5 \mathrm{ppbv}$

$\left.\mathrm{O}_{3}\right]=20 \mathrm{ppb}$

$\left[\mathrm{O}_{3}\right]=60 \mathrm{ppb}$

$\left[\mathrm{O}_{3}\right]=80 \mathrm{ppbv}$

- $\left[\mathrm{O}_{3}\right]=120 \mathrm{ppbv}$

- $[\mathrm{OH}]=0.001 \mathrm{pptv}$

$[\mathrm{OH}]=0.02 \mathrm{pptv}$

$=0.2 \mathrm{ppt}$

$[\mathrm{OH}]=0.3 \mathrm{ppt}$

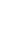




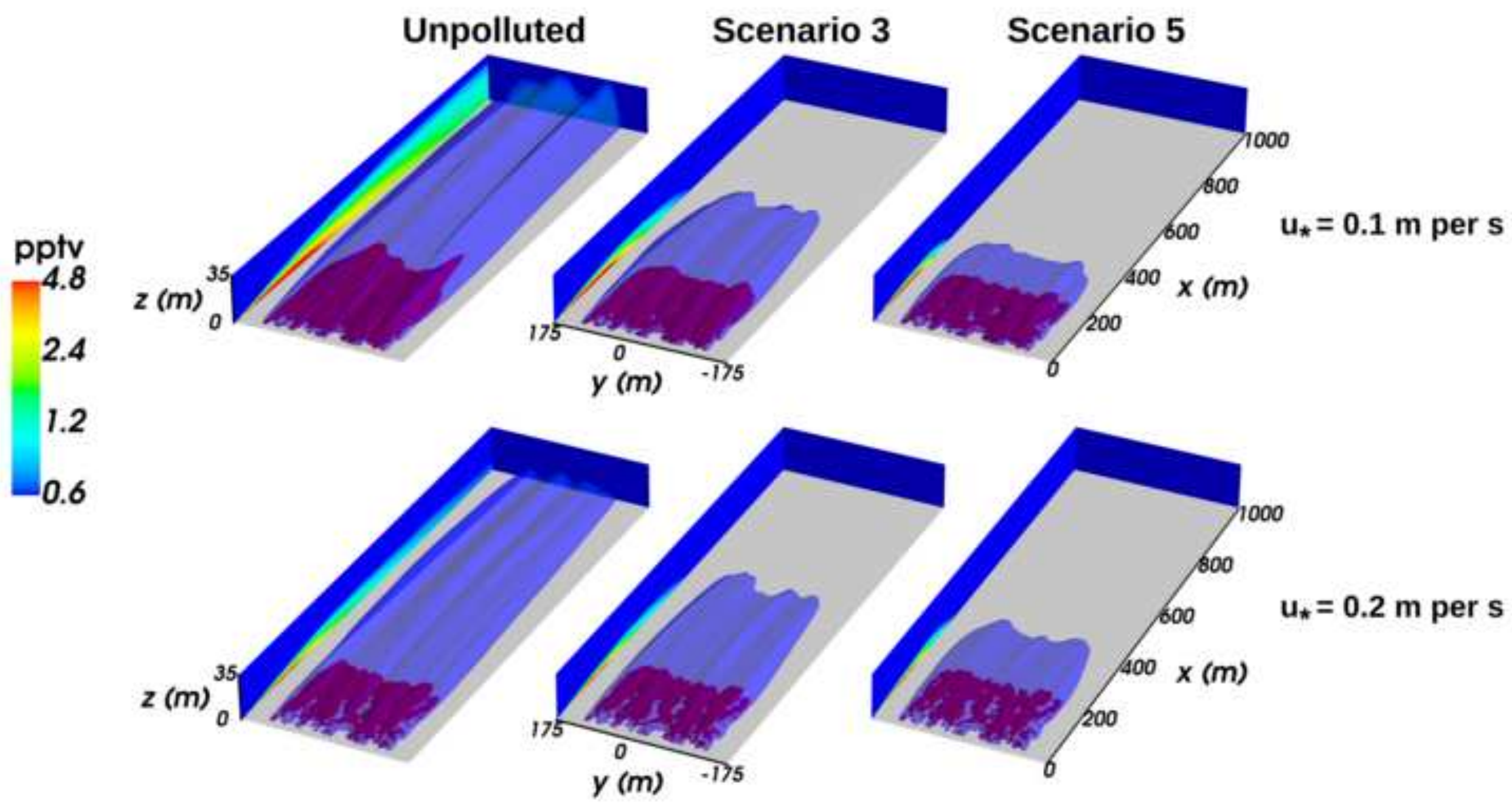




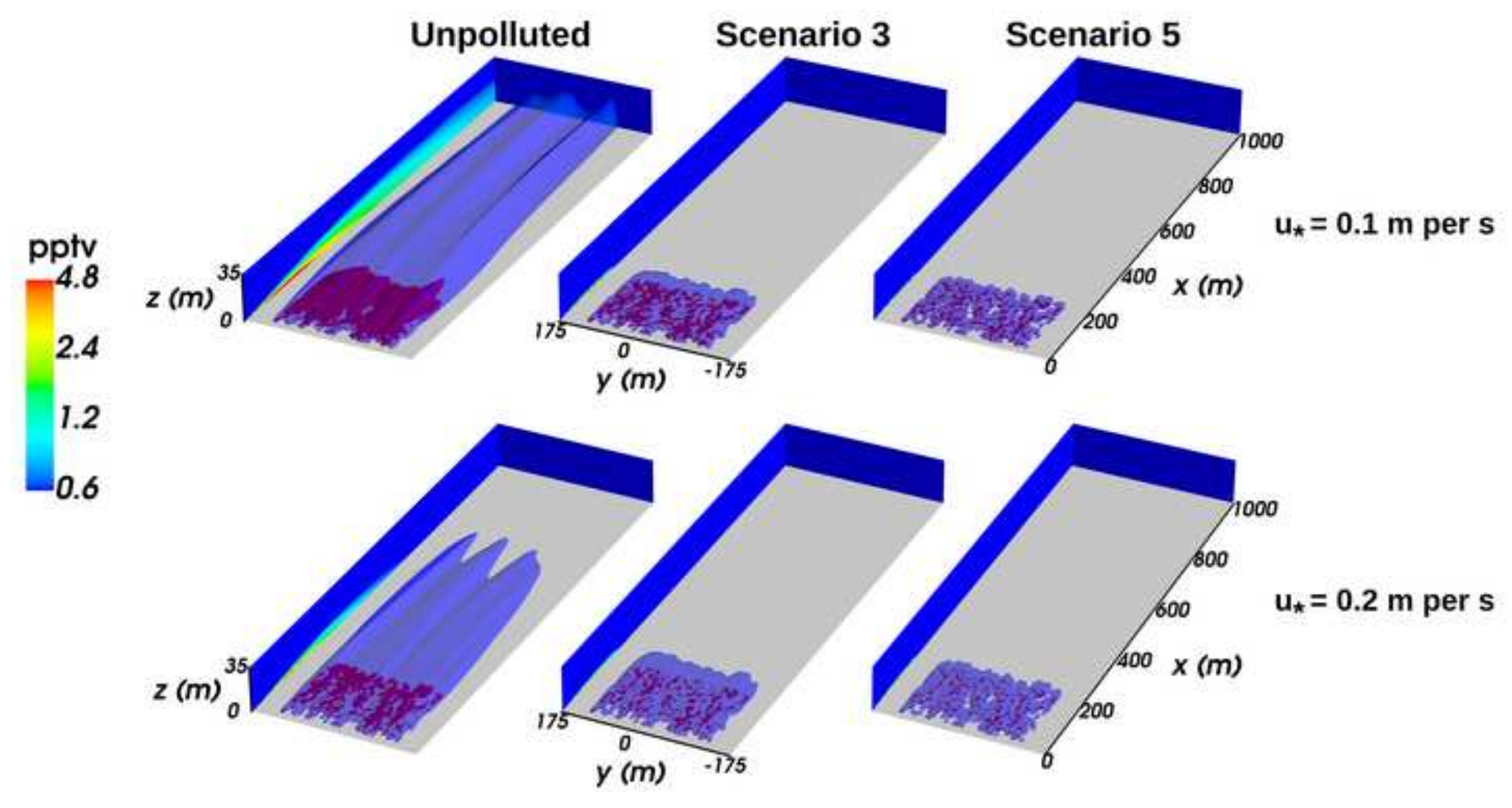



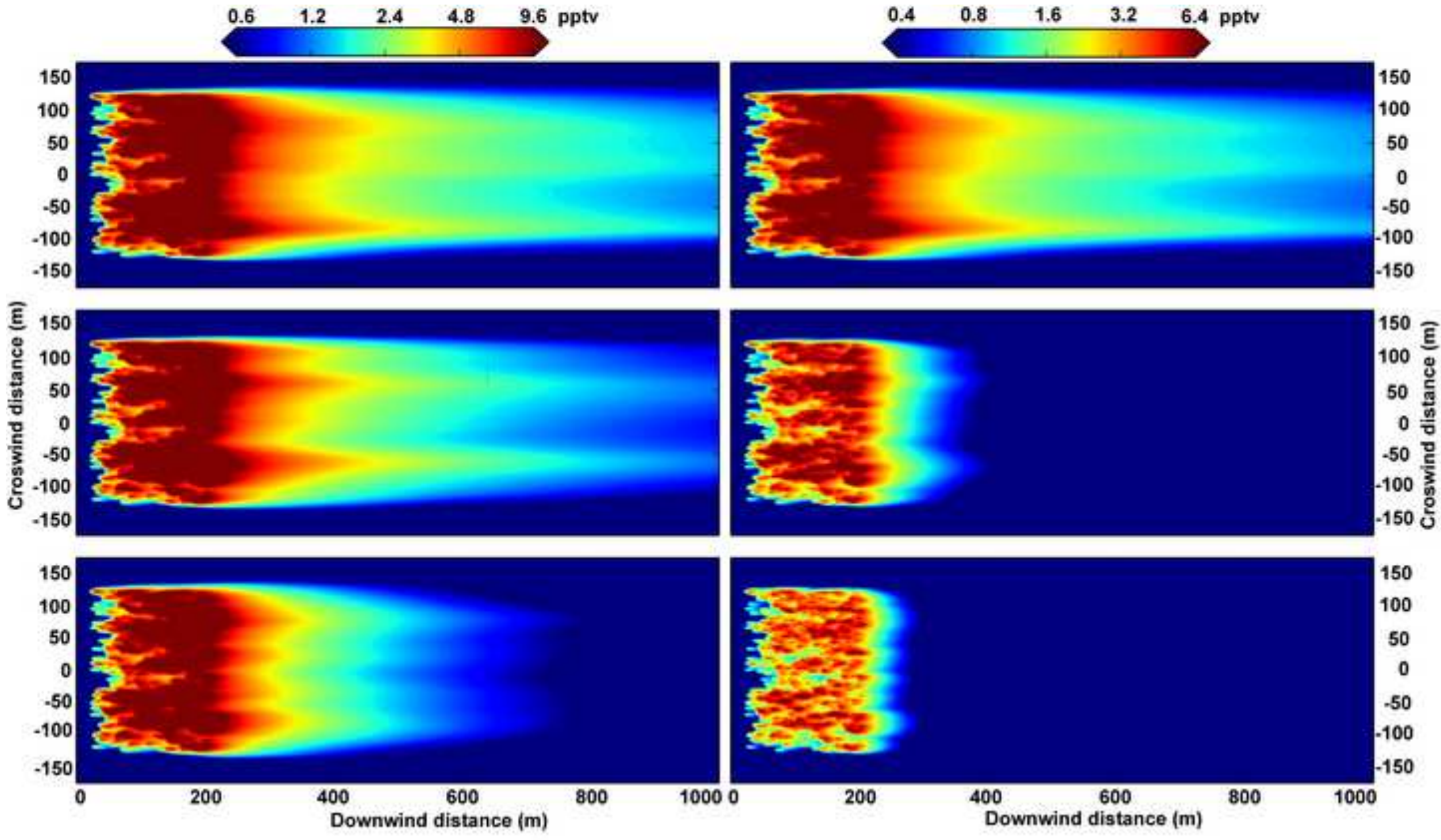

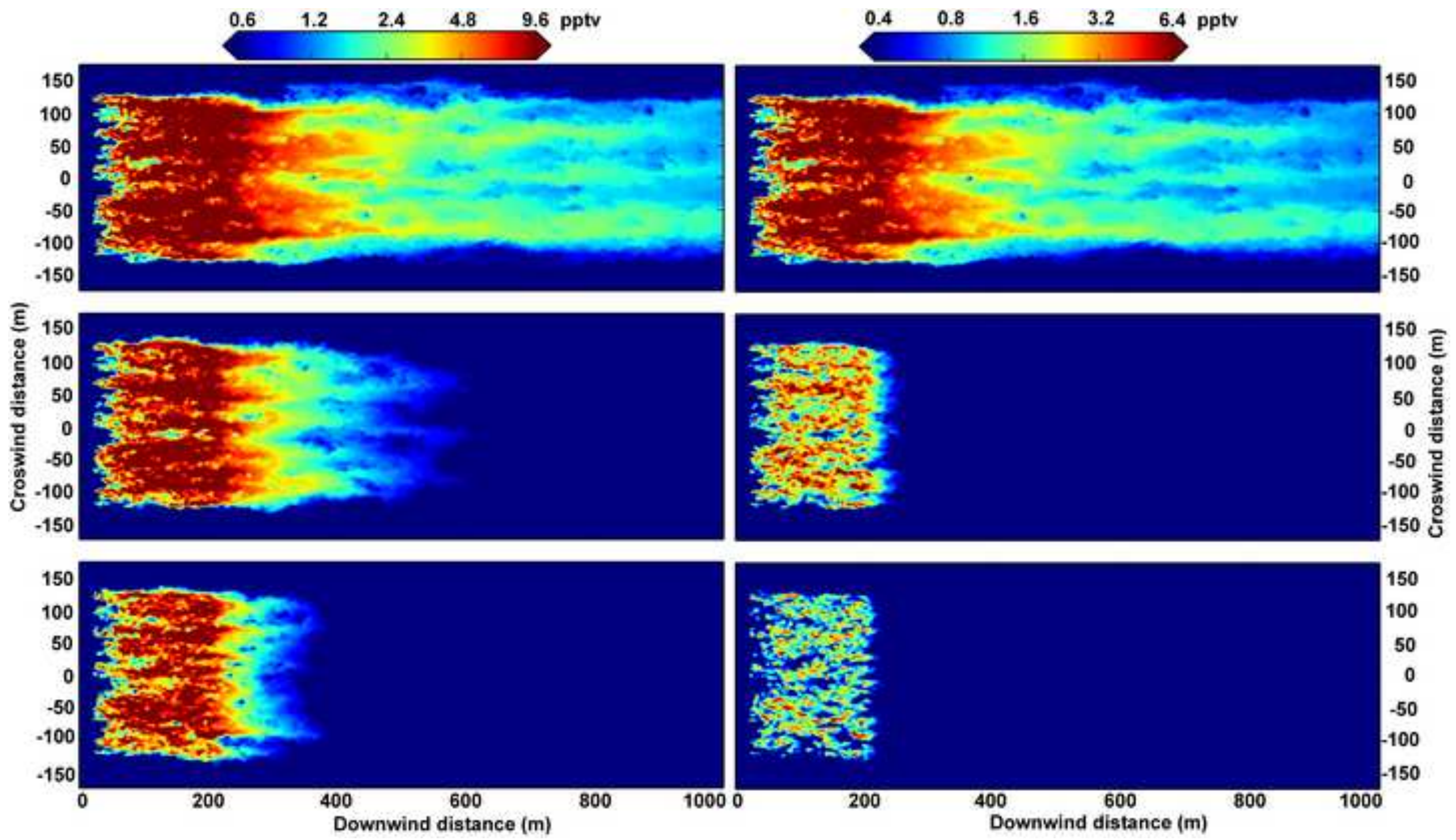

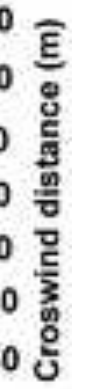

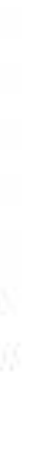




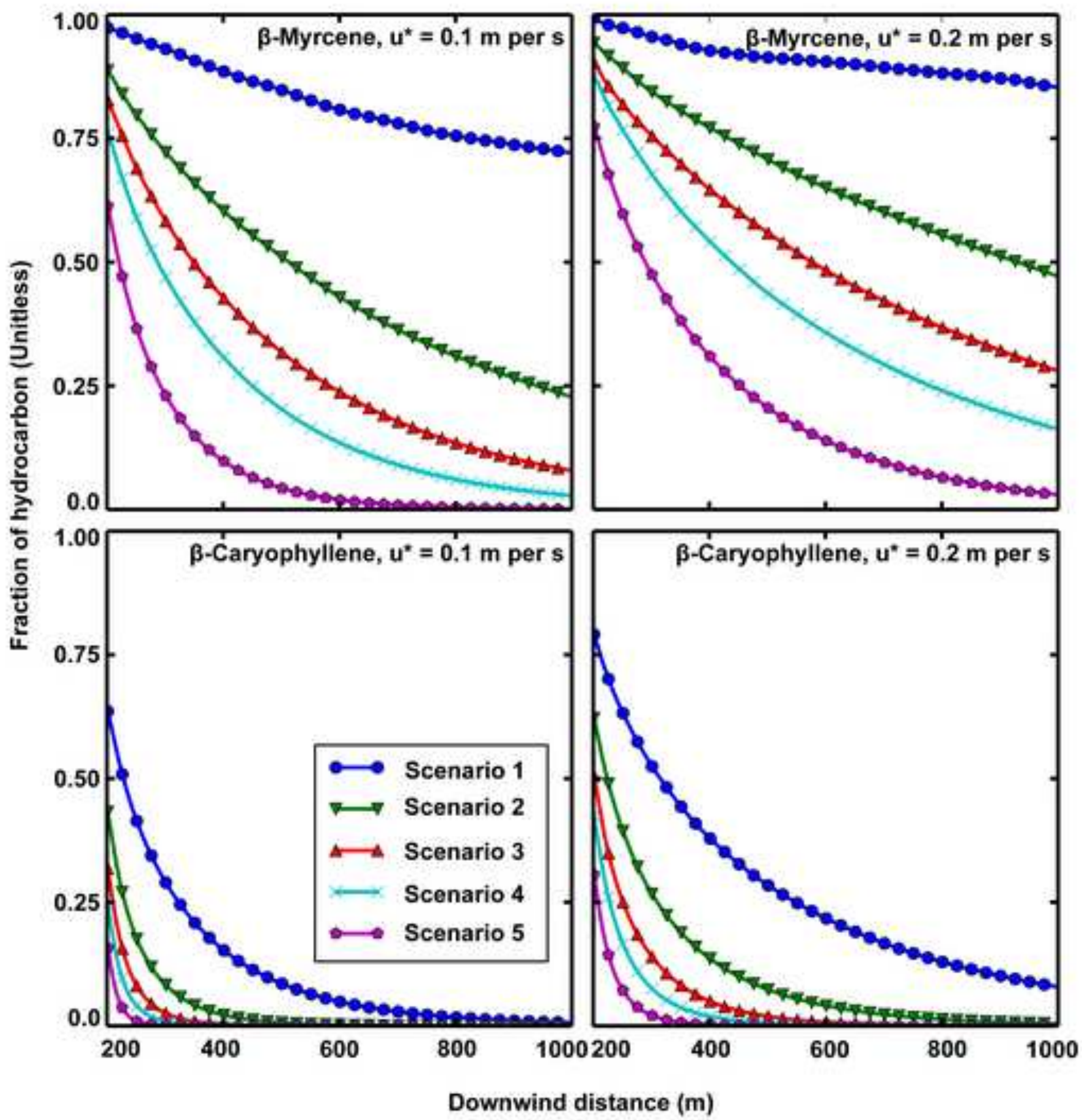



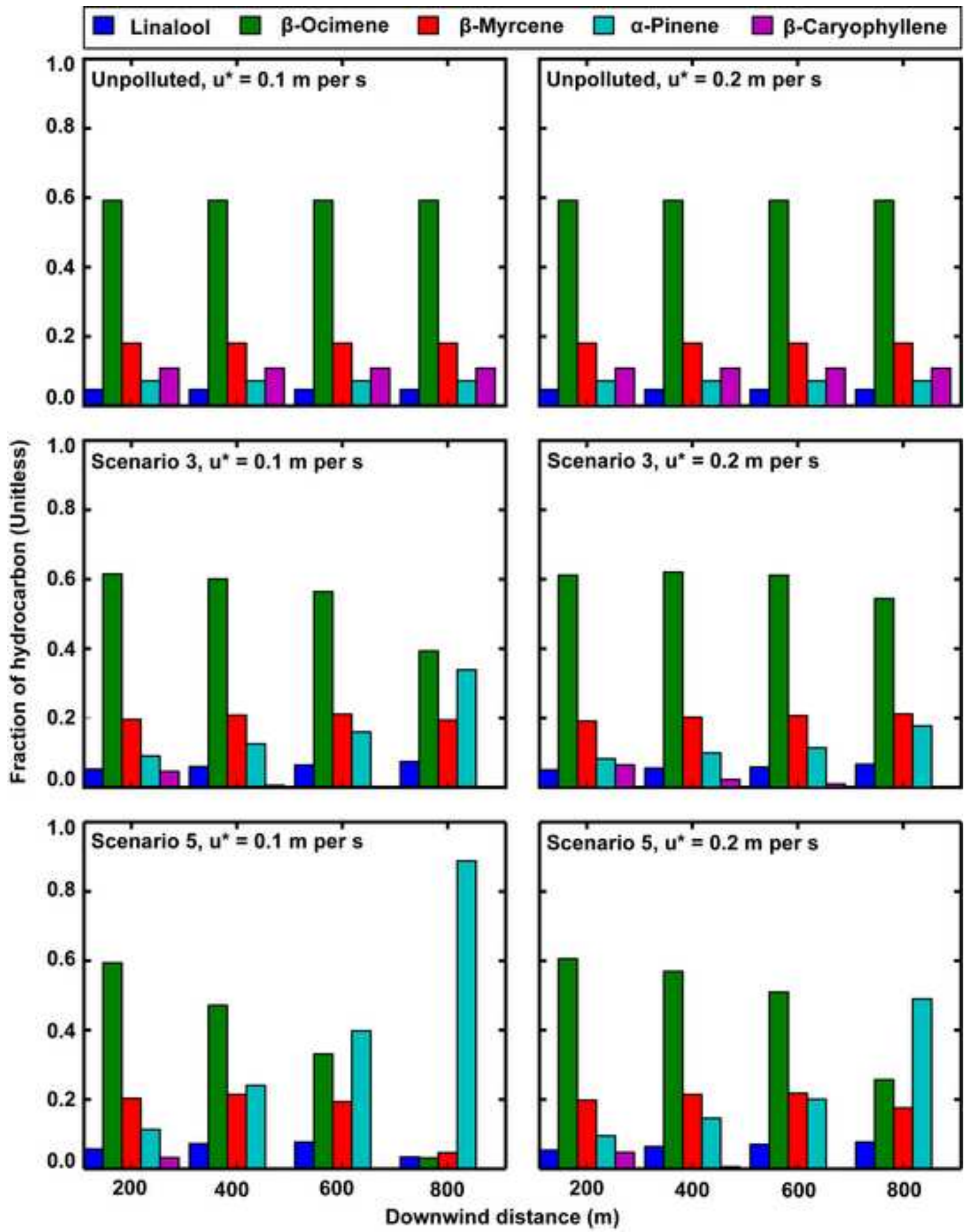


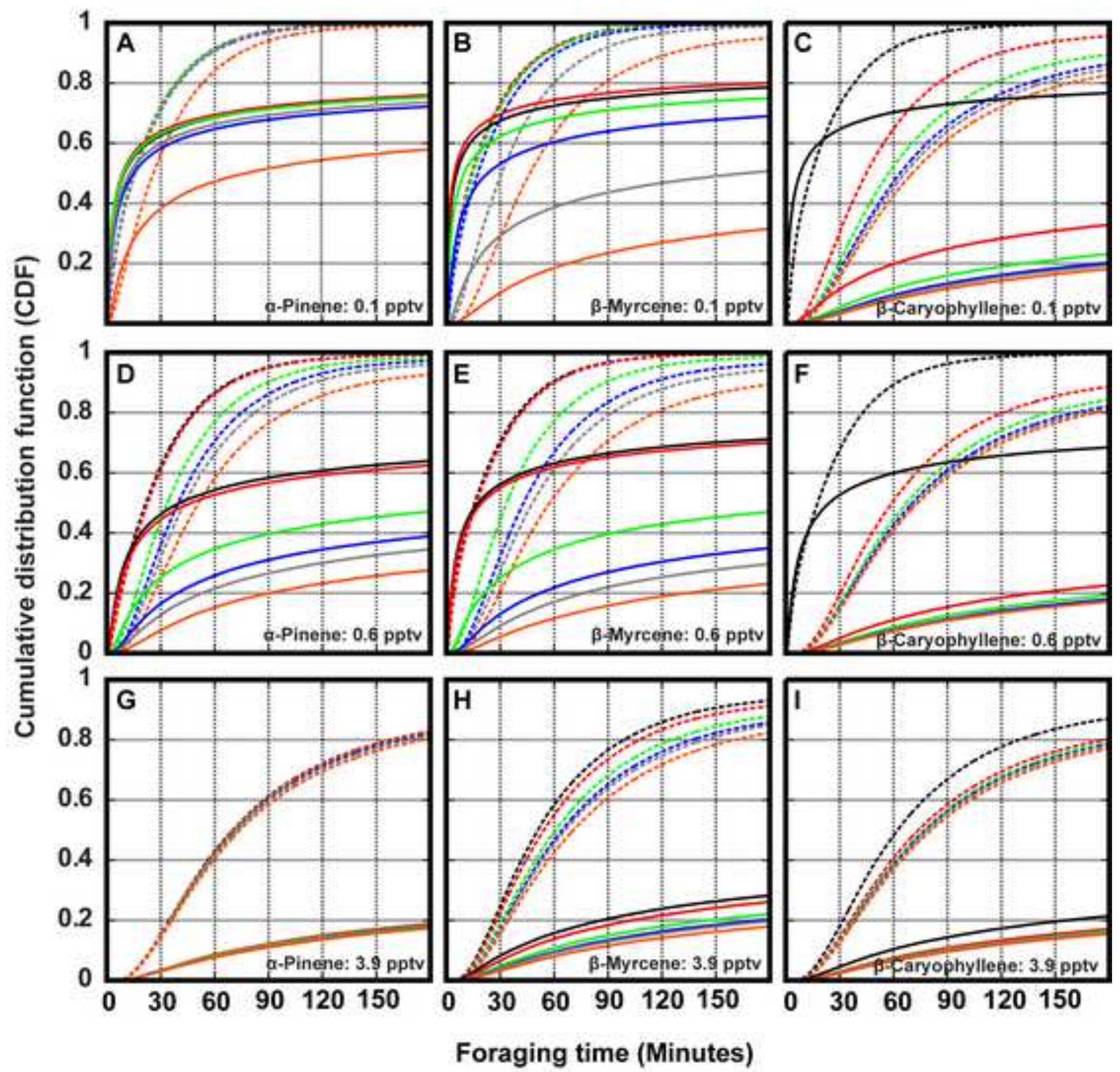

